\title{
Anemia and iron deficiency in inflammatory bowel disease patients in a referral center in Brazil: prevalence and risk factors
}

\author{
Rogério Serafim PARRA ${ }^{1}$, Marley Ribeiro FEITOSA ${ }^{1}$, Sandro da Costa FERREIRA ${ }^{2}$, \\ José Joaquim Ribeiro da ROCHA ${ }^{2}$, Luiz Ernesto de Almeida TRONCON² and Omar FÉRES ${ }^{1}$
}

\begin{abstract}
Background - Data regarding the prevalence of anemia in inflammatory bowel disease (IBD) patients are scarce in Brazil. Anemia and iron deficiency anemia have been known to cause significant functional impairment, lower quality of life, and higher morbidity and mortality and may be correlated with an impact on the cost of treatment. Objective - The aim of this study was to estimate the prevalence and risk factors for anemia and iron deficiency anemia in patients with IBD in a tertiary IBD unit in Southeast Brazil. Methods - We conducted an Institutional Review Board-approved retrospective analysis of an adult IBD cohort (IBD Unit, Ribeirão Preto Medical School, University of São Paulo, Brazil) consisting of 579 patients between January 2014 and July 2018. Clinicoepidemiological data, hemoglobin measurements and serum ferritin were extracted from electronic medical records. Anemia prevalence was calculated among ulcerative colitis (UC) and Crohn's disease (CD) phenotypes. Risk factors for anemia were also calculated. Results - A total of 529 (91\%) patients had complete blood counts available in their medical records. Only $35.5 \%$ of IBD patients were fully screened for anemia. The prevalence of anemia in IBD patients was $24.6 \%(29.1 \%$ in CD and $19.1 \%$ in UC, $P=0.008)$. The anemia was moderate to severe in $16.9 \%(19.8 \%$ in $\mathrm{CD}$ and $11.4 \%$ in UC, $P=0.34)$. The prevalence of iron deficiency was $52.3 \%(53.6 \%$ in $\mathrm{CD}$ and $51.2 \%$ in UC, $P=0.95$ ). Anemia of chronic disease was present in $14.1 \%$ of IBD patients. A total of $53.8 \%$ of patients with anemia were in clinical remission. $\mathrm{CD}$ was associated with an increased prevalence of anemia $(P=0.008 ; \mathrm{OR}=1.76 ; \mathrm{CI} 95 \%=1.16-2.66)$ compared to UC. The penetrant disease phenotype in $\mathrm{CD}$ was associated with a lower risk of anemia $(P<0.0001 ; \mathrm{OR}=0.25 ; \mathrm{CI} 95 \%=0.14-0.43)$. Active disease compared to the disease in clinical remission was associated with an increased risk of anemia $(P=0.0003$; OR $=2.61$; CI 95\% $=1.56-4.36)$ in CD. The presence of anemia was less frequent in patients with $\mathrm{CD}$ who underwent surgical bowel resection compared to those who did not undergo surgery $(P<0.0001 ; \mathrm{OR}=0.24 ; \mathrm{CI}$ $95 \%=0.14-0.40)$. No differences in anemia prevalence were observed regarding CD localization, age at diagnosis, UC extension or biological therapy $(P>0.05)$. Conclusion - Despite the low levels of full screening, anemia and iron deficiency anemia were common manifestations of IBD. CD was associated with an increased risk of anemia, especially with active disease. In addition, patients with CD who underwent surgical bowel resection and penetrant disease phenotype in $\mathrm{CD}$ were associated with lower risk of anemia.
\end{abstract}

HEADINGS - Anemia. Iron deficiency anemia. Risk factors. Prevalence. Inflammatory bowel diseases. Crohn's disease. Proctocolitis.

\section{INTRODUCTION}

Anemia is the most common systemic complication and extraintestinal manifestation of inflammatory bowel disease $(\mathrm{IBD})^{(1-3)}$. It has been associated with complications such as fatigue, impaired quality of life, absenteeism and productivity loss, even in the absence of specific symptoms ${ }^{(4-7)}$. The impact of anemia on the quality of life of IBD patients is substantial, and it affects various aspects of life, such as physical, emotional, and cognitive functions ${ }^{(6,8)}$. It may also increase hospitalization and healthcare costs, especially if inappropriate diagnostic and therapeutic approaches are implemented ${ }^{(7)}$.

The prevalence of anemia is higher in IBD patients than in the general population. Iron deficiency with or without anemia has been reported to affect $13 \%-90 \%$ of IBD patients, depending on some characteristics of the studied population (e.g., gender, age at diagnosis, disease activity, hospitalization and previous surgeries) ${ }^{(4,8-15)}$. In most cases, IBD-associated anemia is due to the combination of chronic iron deficiency anemia (IDA) and anemia of chronic disease $(\mathrm{ACD})^{(1,16-18)}$

Recently, Akhuemonkhan et al. ${ }^{(17)}$ showed that most patients with IBD $(67 \%)$ are screened for anemia at least once during the median 2-year follow-up period. However, very few patients were screened annually as recommended by the guidelines. Moreover, the majority of anemia patients did not undergo laboratory tests (i.e., ferritin) to diagnose IDA as recommended ${ }^{(1)}$.

Declared conflict of interest of all authors: Parra RS has received fees for serving as a speaker and/or an advisory board member for AbbVie, Ferring Pharmaceuticals, Janssen, and Takeda. Feitosa MR has received fees for serving as a speaker and/or an advisory board member for Nestlé, and Janssen. Ferreira SC has received fees for serving as a speaker and/or an advisory board member for Janssen, and Takeda. Rocha JJR, Troncon LEA and Féres O have no conflicts of interest to declare. Disclosure of funding: no funding received

${ }^{1}$ Departamento de Cirurgia e Anatomia, Faculdade de Medicina de Ribeirão Preto, Universidade de São Paulo, Ribeirão Preto, SP, Brasil. ${ }^{2}$ Departamento de Clínica Médica, Faculdade de Medicina de Ribeirão Preto, Universidade de São Paulo, Ribeirão Preto, SP, Brasil.

Corresponding author: Rogério Serafim Parra. E-mail: rsparra@hcrp.usp.br 
Recent studies have shown a high incidence and prevalence of IBD in Brazil ${ }^{(19,20)}$. However, there are no precise data on the frequency of IBD-associated anemia in our population. Thus, it is important to increase the knowledge about IDA and IBD-related anemia in our country and apply the guidelines of screening and follow-up of anemia and IDA in patients with IBD.

The aim of this study was to estimate the prevalence of anemia and IDA in IBD patients in a tertiary IBD unit in Southeast Brazil and to determine the risk factors for this complication in both Crohn's disease (CD) or ulcerative colitis (UC) patients.

\section{METHODS}

\section{Study population and data collection}

The study was conducted in the IBD Unity of Ribeirão Preto Medical School, University of São Paulo, Brazil. Our IBD Unit keeps a prospective electronic database of all medical records. We performed a retrospective review of all medical consultations from January 2014 to January 2018 after approval from our Institutional Review Board. All IBD diagnoses were made by specialists according to standard clinical, radiological and pathological criteria.

The following data were extracted: clinical and endoscopic activity, hemoglobin, hematocrit, serum ferritin, transferrin saturation (TSAT), mean corpuscular hemoglobin $(\mathrm{MCH})$, mean corpuscular hemoglobin concentration (MCHC), mean corpuscular volume $(\mathrm{MCV})$, and $\mathrm{C}$-reactive protein (CRP). Biomarkers were considered for analysis if collected 3 months before or after clinical and mucosal appraisal. We also evaluated ongoing medication, previous surgeries, and age at diagnosis and compared CD phenotype and UC extension with anemia prevalence.

\section{Clinical and endoscopic evaluation}

Clinical activity in UC was defined as a Mayo partial score $>1$ and in $\mathrm{CD}$ as a Harvey-Bradshaw index $(\mathrm{HBI})>4$. Endoscopic activity was defined in $\mathrm{UC}$ as an endoscopy Mayo score $>1$ and, in $\mathrm{CD}$, as a simple endoscopic score of Crohn's disease (SES-CD) $>3$. In CD patients with ileal and/or jejunal disease, endoscopic activity or remission was considered based on radiographic criteria assessed using magnetic resonance enterography or computed tomography.

Anemia was defined as a hemoglobin concentration below 13 $\mathrm{g} / \mathrm{dL}$ for males and $12 \mathrm{~g} / \mathrm{dL}$ for females, according to World Health Organization (WHO) criteria $^{(21)}$ and ECCO guidelines ${ }^{(1)}$. It is difficult to differentiate iron deficiency and ACD, the 2 most frequent types of anemia. Various guidelines and methods of proceedings suggest that the diagnosis should be guided by serum ferritin concentration $^{(22)}$. In our study, the diagnosis of iron deficiency in patients without clinical, endoscopic, or biochemical evidence of active disease was serum ferritin $<30 \mu \mathrm{g} / \mathrm{lL}$. Accordingly, IDA is likely if the ferritin is below $30 \mathrm{mg} / \mathrm{L}$. In the presence of inflammation (fecal calprotectin $>250 \mathrm{mg} / \mathrm{kg}$ and/or CRP $>5 \mathrm{mg} / \mathrm{L}$ ), and TSAT below $20 \%$, a serum ferritin level up to $100 \mu \mathrm{g} / \mathrm{L}$ was considered an iron deficiency. Accordingly, ACD can be diagnosed when ferritin is above $100 \mathrm{mg} / \mathrm{L}$ and TSAT below $20 \%$.

\section{Statistical analysis}

Normal quantitative variables are reported as the mean \pm SD. The prevalence of anemia was assumed to follow a Poisson distribution, and the incidence rate with a $95 \%$ confidence interval (CI) was calculated accordingly. The potential differences between patients with $\mathrm{CD}$ and $\mathrm{UC}$ in relation to the prevalence and factors associated with the occurrence of anemia were evaluated using the two-tailed Fisher exact test, which was also used to estimate the odds ratio (OR) and its $95 \%$ confidence interval $(95 \% \mathrm{CI})$. A multivariate analysis (logistic regression) was performed to identify independent variables associated with anemia. Statistical analyses were performed using GraphPad Instat 3.05 software. The level of significance was set at $P<0.05$.

\section{Ethical considerations}

The study was approved by the Hospital's Ethics Committee of Ribeirão Preto Medical School, University of São Paulo (\# 3.117.993).

\section{RESULTS}

A total of 579 patients were evaluated in the selected period. Recent complete blood testing results were available in $529(91.3 \%)$ patients. IDA was calculated in $205(35.5 \%)$ patients. The prevalence of anemia in IBD patients was $25.3 \%$. TABLE 1 summarizes the patient characteristics.

TABLE 1. Demographic characteristics of IBD patients $(n=529)$.

\begin{tabular}{lccc}
\hline Characteristics & CD (n=296) & UC $(\mathbf{n}=233)$ & $P$ value \\
\hline Mean age (years) & 43.8 & 47.1 & 0.01 \\
Gender (\%) & & & \\
$\quad$ Male & 52.4 & 41.2 & 0.01 \\
Female & 47.6 & 58.8 & 0.01 \\
Mean age at diagnosis (years) & 30.2 & 35.1 & 0.03 \\
Disease duration (years) & 13.9 & 12.5 & 0.07 \\
Moderate to severe disease (\%) & 86.8 & 74.2 & $<0.001$ \\
Biological therapy (\%) & 65.2 & 25.8 & $<0.001$ \\
Concomitant & 57.4 & 31.2 & $<0.001$ \\
Immunosuppression (\%) & & & \\
Montreal classification & & & \\
Location of CD (\%) & & - & - \\
L1 & 30.1 & - & - \\
L2 & 14.5 & - & - \\
L3 & 55.5 & & - \\
Behavior of CD (\%) & & - & - \\
B1 & 26.3 & - & - \\
B2 & 22.4 & - & - \\
B3 & 51.3 & - & - \\
P & 35.8 & & - \\
Extent of UC (\%) & & & - \\
E1 & - & 21.0 & - \\
E2 & - & 51.0 & - \\
E3 & & & - \\
\hline
\end{tabular}

$\mathrm{N}$ : number of patients expressed as a percentage; IBD: inflammatory bowel disease; CD: Crohn's disease; UC: ulcerative colitis.

We observed a higher prevalence of male patients with $\mathrm{CD}$ and female patients with $\mathrm{UC}(P=0.01)$. We also observed that the mean age at IBD diagnosis was lower in patients with $\mathrm{CD}$ than in patients with UC, and according to the severity of IBD, $81.1 \%$ of patients were moderate to severe. Patients with $\mathrm{CD}$ had a greater chance of being moderate to severe, as well as a higher chance of being under biological therapy or immunosuppressor treatment $(P<0.001)$. 
$\mathrm{CD}$ was associated with an increased prevalence of anemia $(P=0.008 ;$ OR $=1.76 ;$ CI $95 \%=1.16-2.66)$ compared to ulcerative colitis (FIGURE 1). The penetrant disease phenotype in CD was associated with a lower risk of anemia $(P<0.0001$; OR $=0.25$; CI $95 \%$ $=0.14-0.43)$. Active disease compared to the disease in clinical remission was associated with an increased risk of anemia $(P=0.0003$; $\mathrm{OR}=2.61$; CI $95 \%=1.56-4.36)$ in CD. The presence of anemia was less frequent in patients with CD who underwent surgical bowel resection compared to those who did not undergo surgery of bowel resection $(P<0.0001 ; \mathrm{OR}=0.24$; CI 95\% $=0.14-0.40)$. Differences were not observed in the presence of anemia and localization of $\mathrm{CD}$, age at diagnosis, extension of UC and use of biological factors $(P>0.05)$. These results are summarized in TABLE 2.

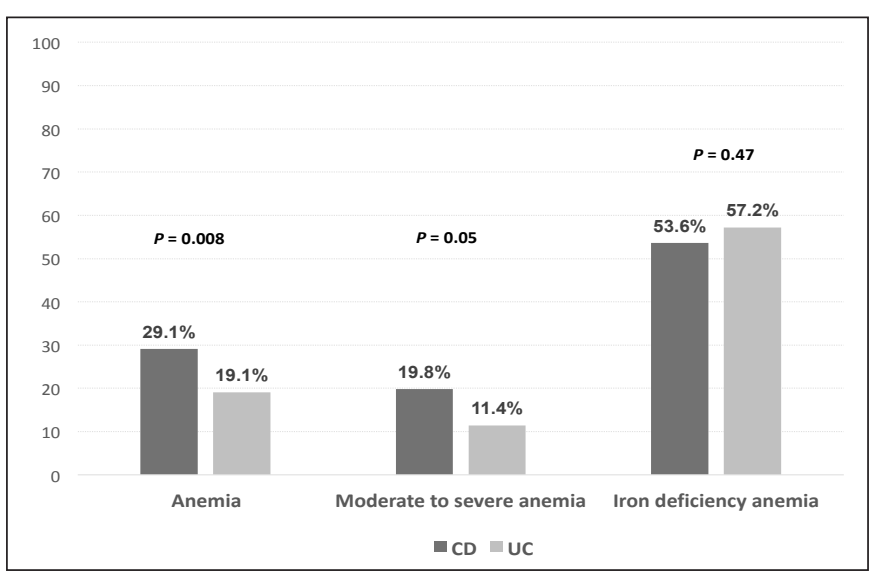

FIGURE 1. Percentage of anemia, moderate to severe anemia and iron deficiency anemia in CD and UC patients. $P$ value for statistical tests over the two groups (CD and UC). * and ** Fisher's exact test.

TABLE 2. Factors associated with risk of anemia.

\begin{tabular}{lcc}
\hline Risk factor & OR; CI 95\% & $P$ value \\
\hline CD & $1.76(1.16-2.66)$ & 0.008 \\
Penetrant disease phenotype (CD) & $0.25(0.14-0.43)$ & $<0.0001$ \\
Active disease (IBD) & $2.61(1.56-4.36)$ & 0.003 \\
CD who underwent surgical resection & $0.24(0.14-0.40)$ & $<0.0001$ \\
\hline
\end{tabular}

OR: odds ratio. CI95\%, 95\% confidence interval; IBD: inflammatory bowel disease; CD Crohn's disease.

\section{DISCUSSION}

Approximately one-third of patients with IBD were fully screened for anemia during the median 4-year follow-up period (41.5\% in CD and $35.2 \%$ in UC, $P=0.486$ ). This means that almost two-thirds of patients did not undergo correct screening as recommended $^{(1,12,22,23)}$. Iron deficiency anemia (IDA) was also very common in both diseases (UC and CD, 52.7 and 53.6\%, respectively).

Despite being the most common extraintestinal manifestation of IBD, anemia is not well recognized and is not adequately treated by IBD specialists, even in referral centers. Moreover, many IBD units do not have specific protocols for anemia investigation and management. Nevertheless, anemia is associated with higher rates of postoperative complications, hospitalizations, costs, morbidity and mortality as well as a negative impact on quality of life in IBD patients ${ }^{(5,8,15,23,24)}$. Therefore, recognition of the problem is important, and it needs appropriate diagnostic and therapeutic approaches.
The burden of anemia has an impact on individual IBD patients and affects the healthcare system. In the United States, for instance, the additional annual cost of one anemic IBD patient compared with one nonanemic IBD patient has been estimated to be $\$ 7406^{(17)}$. Although we did not calculate the costs of anemia in this study, we previously presented data about the healthcare resources in CD and UC and noticed that anemia was related to high healthcare usage and lower quality of life $\mathrm{e}^{(25-27)}$.

Our study showed a prevalence of anemia of $25.3 \%$. The majority of patients had mild anemia $(83 \%)$. This finding is in accordance with an overall prevalence of anemia (24\%) found in a meta-analysis evaluating 2192 IBD patients in European countries $(27 \%$ in CD and $21 \%$ in UC) ${ }^{(28)}$. Lupu et al. ${ }^{(11)}$ showed that anemia was present in $32.2 \%$ of IBD patients in Romania. Another study showed that anemia was identified in 244 patients, representing a prevalence of $18.6 \%{ }^{(4)}$. Anemia was more frequent in patients with active disease $(\mathrm{HBI}>4$; SCCAI $>2)$ than in those in clinical remission (33.6 vs $15.6 \%, P<0.001)$.

It is important to emphasize that measurement of hemoglobin levels and serum iron alone is insufficient: hemoglobin measurements only allow diagnosis of the third and last stage of $\operatorname{IDA}^{(1,18)}$. Thus, it is possible that the prevalence of iron deficiency is underestimated, especially if measurement of serum ferritin is not part of the routine diagnosis. In our study, IDA was present in $57.2 \%$ of UC patients and $53.6 \%$ of CD patients. This is in accordance with other studies that show high rates of iron laboratory disorders (anemia and/or iron deficiency anemia) in patients with $\operatorname{IBD}^{(29,30)}$.

To our knowledge, our study is the largest in number of patients evaluated ( $n=529)$, showing the prevalence of anemia in IBD patients in our country. There are at least two Brazilian studies that evaluated the prevalence and significance of anemia in IBD patients in Brazil. Alves et al. ${ }^{(31)}$ conducted a cross-sectional study at a federal university in São Paulo. They included 44 patients with $\mathrm{CD}$ and 55 patients with UC. Anemia and/or iron laboratory disorders were present in $75 \%$ of the patients with $\mathrm{CD}$ and in $78.2 \%$ with UC. Anemia was observed in $20.5 \%$ of the patients with CD and in $23.6 \%$ with UC, which is very similar to ours. Another Brazilian paper showed that in a cross-sectional study with 200 IBD patients $(50 \%$ with $\mathrm{CD})$, the overall prevalence of anemia in IBD was $21 \%{ }^{(13)}$. There was no significant difference in the prevalence of anemia between CD $(24 \%)$ and UC (18\%) patients, which is similar to our study.

Anemia was significantly higher in $\mathrm{CD}$ than $\mathrm{UC}$, which is in strong agreement with most of the previous research ${ }^{(17,28,32,33)}$. In the present study, we observed that the risk of anemia was higher in patients with CD than in patients with UC $(29.1 \%$ vs $19.1 \%$, OR; CI 95\%, $1.76(1.16-2.66), P=0.008)$. One possible explanation is that a higher proportion of $\mathrm{CD}$ patients in our cohort were moderate to severe (CD: $86.8 \%$, UC $74.2 \%, P<0.001)$. Burisch et al. ${ }^{(32)}$ reported a higher prevalence of anemia in $\mathrm{CD}$ patients than in UC patients, and overall, $49 \%$ of CD patients and $39 \%$ of UC patients experienced at least one instance of anemia during the first 12 months after diagnosis. There were no differences between sexes (male/female), although other studies have shown that female sex is a strong risk factor for anemia in IBD.

Our study showed that active disease is associated with a higher risk of developing anemia. This is in accordance with Antunes et al. ${ }^{(13)}$ who showed that moderate disease activity (OR: 3.48, 95\% CI, 1.95-9.64, $P=0.002$ ) and elevated CRP levels (OR: $1.8,95 \% \mathrm{CI}, 1.04-3.11, P=0.02)$ were independently associated 
with anemia. Alves et al. ${ }^{(31)}$ observed that anemia was associated with the disease activity index in UC but not in CD. Many authors have shown that activity is associated with higher risk or anemia, similar to our data ${ }^{(8,34,35)}$. Active disease is associated with at least two factors that increase the risk of anemia in IBD patients. First, patients with active disease have diarrhea, loss of blood and loss of appetite. Second, because of chronic inflammation, the absorption of iron from enterocytes is blocked due to elevated serum hepcidin levels ${ }^{(22)}$.

Although anemia is associated with active disease, it is important to emphasize that at least $40 \%$ of patients in clinical remission had anemia or IDA. These data emphasize the importance of continuous surveillance, as IBD patients can develop anemia and/ or ID regardless of disease activity ${ }^{(4)}$.

Patients with CD and structuring or inflammatory behavior had an increased risk of anemia compared to patients with a penetrant phenotype $(P<0.0001)$. However, there was no association between anemia and disease location (in CD and UC). The higher risk of anemia in patients with inflammatory behavior can also be explained by loose blood on the stool, loss of appetite and chronic inflammation in these patients.

There was a lower risk of anemia in patients with CD who underwent surgical bowel resection. One explanation is that after surgery and appropriate medical management (medical treatment, nutritional assessment), the majority of CD patients improved, gained weight, and, consequently, increased their hemoglobin levels ${ }^{(36)}$. This study was retrospective, so we cannot state if the patients had anemia before surgery, and it was corrected.

This study demonstrated the magnitude of anemia in Brazilian patients with IBD. However, it has some limitations. First, the causality relationship could not be established, given the retrospective nature of the study, without a follow-up period. Second, despite the number of patients included, it was a single-center experience and did not include any other IBD Unity from São Paulo State or the Southeast Region of Brazil. Third, some variables were not available in medical records, such as steroid usage or smoking. Fourth, we did not evaluate the prevalence of anemia in the pediatric population. However, the prevalence of anemia in children and adolescents has been published and mostly agrees with our adult data $^{(34,35,37)}$. Finally, the current study may not represent the general Brazilian population with IBD because the study was conducted with IBD patients with more severe conditions who are being followed at a tertiary referral university hospital.

\section{CONCLUSION}

Despite the presence of these significant implications, anemia still remains underestimated and untreated in IBD patients. CD was associated with an increased risk of anemia, especially with active disease. On the other hand, patients with $\mathrm{CD}$ who underwent surgical bowel resection and penetrant disease phenotype in $\mathrm{CD}$ were associated with lower risk of anemia. Anemia should be recognized, investigated and treated in IBD patients.

\section{ACKNOWLEDGEMENTS}

The authors thank Dr. Rodrigo Saad Rodrigues, Dr. Beatriz Edila Caetano e Dr. Aureo Favoretto Júnior (HCFMRP-USP) for data collection. The authors thank Dr. Aysegül Aksan (Interdisciplinary Crohn Colitis Center Rhein-Main, Frankfurt am Main, Germany) for suggestions and manuscript revision.

\section{Authors' contribution}

Parra RS: study design, data collection, data analysis, data interpretation, and manuscript writing. Feitosa MR: collection, data analysis and interpretation. Ferreira SC: data analysis, interpretation and statistical analysis. Rocha JJR, Troncon LEA, Féres O: critical revising.

All authors contributed to the analysis and interpretation of data, revision of the manuscript for important intellectual content, granted final approval of the version to be published and agreed to be accountable for all aspects of the work in ensuring that questions related to the accuracy or integrity of any part of the work are appropriately investigated and resolved.

\section{Orcid}

Rogério Serafim Parra: 0000-0002-5566-9284.

Marley Ribeiro Feitosa: 0000-0002-4440-2023.

Sandro da Costa Ferreira: 0000-0001-7698-6599.

José Joaquim Ribeiro da Rocha: 0000-0001-7118-0545.

Luiz Ernesto de Almeida Troncon: 0000-0002-8599-2410.

Omar Féres: 0000-0003-3593-0526. 
Parra RS, Feitosa MR, Ferreira SC, Rocha JJR, Troncon LEA, Féres O. Anemia e deficiência de ferro em pacientes com doença inflamatória intestinal em um centro de referência no Brasil: prevalência e fatores de risco. Arq Gastroenterol. 2020;57(3):272-7.

RESUMO - Contexto - Dados referentes à prevalência de anemia em pacientes com doença inflamatória intestinal (DII) são escassos no Brasil. Sabe-se que anemia e a anemia ferropriva causam comprometimento funcional significativo, menor qualidade de vida e maior morbimortalidade e podem estar correlacionadas com um impacto no custo do tratamento. Objetivo - $\mathrm{O}$ objetivo deste estudo foi estimar a prevalência e os fatores de risco de anemia e de anemia ferropriva em pacientes com DII em um centro de referência de DII no Sudeste do Brasil. Métodos - Realizamos uma análise retrospectiva dos pacientes com DII adultos, aprovada pelo Comitê de Ética Institucional do Hospital das Clínicas da Faculdade de Medicina de Ribeirão Preto da Universidade de São Paulo, Brasil, constituída por 579 pacientes no período de janeiro de 2014 a julho de 2018 . Dados clínico-epidemiológicos, níveis de hemoglobina e de ferritina sérica foram obtidos dos prontuários eletrônicos. A prevalência de anemia foi calculada entre os fenótipos de retocolite ulcerativa (RCU) e doença de Crohn (DC). Fatores de risco para anemia também foram calculados. Resultados - Um total de 529 (91\%) pacientes tinha disponível o exame de hemograma completo em seus prontuários médicos. Apenas 35,5\% dos pacientes com DII tinha o rastreamento completo para anemia. A prevalência de anemia nos pacientes com DII foi de $24,6 \%(29,1 \%$ na DC e $19,1 \%$ na RCU, $P=0,008)$. A anemia foi moderada a grave em $16,9 \%(19,8 \%$ na DC e $11,4 \%$ na RCU, $P=0,34)$. A prevalência de deficiência de ferro foi de $52,3 \%(53,6 \%$ na DC e $51,2 \%$ na RCU, $P=0,95)$. Anemia de doença crônica estava presente em $14,1 \%$ dos pacientes com DII. Um total de $53,8 \%$ dos pacientes com anemia estavam em remissão clínica. A DC esteve associada a um aumento da prevalência de anemia $(P=0,008 ; \mathrm{OR}=1,76 ; \mathrm{IC} 95 \%=1,16-2,66)$ em comparação à RCU. O fenótipo da doença penetrante na DC foi associado a um menor risco de anemia $(P<0,0001 ; \mathrm{OR}=0,25 ; \mathrm{IC} 95 \%=0,14-0,43)$. A doença ativa comparada à doença em remissão clínica foi associada a um risco aumentado de anemia $(P=0,0003 ; \mathrm{OR}=2,61$; IC $95 \%=1,56-4,36)$ na DC. A presença de anemia foi menos frequente nos pacientes com DC submetidos à ressecção intestinal em comparação aos que não foram submetidos à cirurgia $(P<0,0001 ; \mathrm{OR}=0,24 ; \mathrm{IC} 95 \%=0,14-0,40)$. Não foram observadas diferenças na prevalência de anemia em relação à localização da DC, idade ao diagnóstico, extensão da RCU ou terapia biológica $(P>0,05)$. Conclusão - Apesar do baixo rastreamento completo, tanto a anemia como a anemia ferropriva foram manifestações comuns da DII. A DC foi associada a um risco aumentado de anemia, especialmente com doença ativa. Além disto, pacientes com DC submetidos a ressecção intestinal e/ou com fenótipo penetrante tiveram menor risco de anemia.

DESCRITORES - Anemia. Anemia ferropriva. Fatores de risco. Prevalência. Doenças inflamatórias intestinais. Doença de Crohn. Proctocolite.

\section{REFERENCES}

1. Dignass AU, Gasche C, Bettenworth D, Birgegård G, Danese S, Gisbert JP, et al. European consensus on the diagnosis and management of iron deficiency and anaemia in inflammatory bowel diseases. J Crohns Colitis. 2015;9:211-22.

2. Vavricka SR, Brun L, Ballabeni P, Pittet V, Prinz Vavricka BM, Zeitz J, et al. Frequency and risk factors for extraintestinal manifestations in the Swiss inflammatory bowel disease cohort. Am J Gastroenterol. 2011;106:110-9.

3. Eriksson C, Henriksson I, Brus O, Zhulina Y, Nyhlin N, Tysk C, et al. Incidence, prevalence and clinical outcome of anaemia in inflammatory bowel disease: a population-based cohort study. Aliment Pharmacol Ther. 2018;48:638-45.

4. Portela F, Lago P, Cotter J, Gonçalves R, Vasconcelos H, Ministro P, et al. Anaemia in Patients with Inflammatory Bowel Disease - A Nationwide Cross-Sectional Study. Digestion. 2016;93:214-20.

5. Bager P, Befrits R, Wikman O, Lindgren S, Moum B, Hjortswang H, et al. High burden of iron deficiency and different types of anemia in inflammatory bowel disease outpatients in Scandinavia: a longitudinal 2-year follow-up study. Scand J Gastroenterol. 2013;48:1286-93.

6. Danese S, Hoffman C, Vel S, Greco M, Szabo H, Wilson B, et al. Anaemia from a patient perspective in inflammatory bowel disease: results from the European Federation of Crohn's and Ulcerative Colitis Association's online survey. Eur J Gastroenterol Hepatol. 2014;26:1385-91.

7. Wells CW, Lewis S, Barton JR, Corbett S. Effects of changes in hemoglobin level on quality of life and cognitive function in inflammatory bowel disease patients. Inflamm Bowel Dis. 2006;12:123-30.

8. González Alayón C, Pedrajas Crespo C, Marín Pedrosa S, Benítez JM, Iglesias Flores E, Salgueiro Rodríguez I, et al. Prevalence of iron deficiency without anaemia in inflammatory bowel disease and impact on health-related quality of life. Gastroenterol Hepatol. 2018;41:22-9.

9. Wilson A, Reyes E, Ofman J. Prevalence and outcomes of anemia in inflammatory bowel disease: a systematic review of the literature. Am J Med. 2004;116 (Suppl 7A):44S-9S.

10. Blumenstein I, Dignass A, Vollmer S, Klemm W, Weber-Mangal S, Stein J. Current practice in the diagnosis and management of IBD-associated anaemia and iron deficiency in Germany: the German AnaemIBD Study. J Crohns Colitis. 2014;8:1308-14.
11. Lupu A, Diculescu M, Diaconescu R, Tantau M, Tantau A, Visovan I, et al Prevalence of anemia and iron deficiency in Romanian patients with inflammatory bowel disease: a prospective multicenter study. J Gastrointestin Liver Dis. 2015;24:15-20

12. Gomollón F, Gisbert JP. Current management of iron deficiency anemia in inflammatory bowel diseases: a practical guide. Drugs. 2013;73:1761-70.

13. Antunes CV, Hallack Neto AE, Nascimento CR, Chebli LA, Moutinho IL, Pinheiro BoV, et al. Anemia in inflammatory bowel disease outpatients: prevalence, risk factors, and etiology. Biomed Res Int. 2015;2015:728925.

14. Lee DS, Bang KB, Kim JY, Jung YS, Park JH, Kim HJ, et al. The prevalence and clinical characteristics of anemia in Korean patients with inflammatory bowel disease. Intest Res. 2016;14:43-9.

15. Kassebaum NJ, Collaborators GA. The Global Burden of Anemia. Hematol Oncol Clin North Am. 2016;30:247-308.

16. Stein J, Hartmann F, Dignass AU. Diagnosis and management of iron deficiency anemia in patients with IBD. Nat Rev Gastroenterol Hepatol. 2010;7 599-610.

17. Akhuemonkhan E, Parian A, Miller K, Hanauer S, Hutfless S. Prevalence and screening for anaemia in mild to moderate Crohn's disease and ulcerative colitis in the United States, 2010-2014. BMJ Open Gastroenterol. 2017;4:e00155.

18. Aksan A, Farrag K, Stein J. An update on the evaluation and management of iron deficiency anemia in inflammatory bowel disease. Expert Rev Gastroenterol Hepatol. 2019;13:95-7.

19. Gasparini RG, Sassaki LY, Saad-Hossne R. Inflammatory bowel disease epidemiology in São Paulo State, Brazil. Clin Exp Gastroenterol. 2018;11:423-9.

20. Lima Martins A, Volpato RA, Zago-Gomes MDP. The prevalence and phenotype in Brazilian patients with inflammatory bowel disease. BMC Gastroenterol. 2018;18:87.

21. WHO U, UNU. Iron deficiency anemia: assessment, prevention and control. Report of a joint WHO/UNICEF/UNU consultation. World Health Organization2001.

22. Murawska N, Fabisiak A, Fichna J. Anemia of Chronic Disease and Iron Deficiency Anemia in Inflammatory Bowel Diseases: Pathophysiology, Diagnosis, and Treatment. Inflamm Bowel Dis. 2016;22:1198-208. 
23. Rogler G, Vavricka S. Anemia in inflammatory bowel disease: an under-estimated problem? Front Med (Lausanne). 2014;1:58

24. Nielsen OH, Ainsworth M, Coskun M, Weiss G. Management of Iron-Deficiency Anemia in Inflammatory Bowel Disease: A Systematic Review. Medicine (Baltimore). 2015;94(23):e963.

25. Decimoni TC SS, Feitosa MR, Parra RS. Healthcare resource utilization in patients with moderate to severe crohn's disease: a Brazilian real world study. Value Health2017. p. A636.

26. Decimoni TC SS, Feitosa MR, Parra RS. Healthcare resource utilization in patients with moderate to severe ulcerative colitis: a Brazilian real world study. Value Health2017. p. A636-A7.

27. Parra RS, Chebli JMF, Amarante HMBS, Flores C, Parente JML, Ramos O, et al. Quality of life, work productivity impairment and healthcare resources in inflammatory bowel diseases in Brazil. World J Gastroenterol. 2019;25:5862-82.

28. Filmann N, Rey J, Schneeweiss S, Ardizzone S, Bager P, Bergamaschi G, et al. Prevalence of anemia in inflammatory bowel diseases in european countries: a systematic review and individual patient data meta-analysis. Inflamm Bowel Dis. 2014;20:936-45.

29. Lucendo AJ, Arias Á, Roncero Ó, Hervías D, Verdejo C, Naveas-Polo C, et al. Anemia at the time of diagnosis of inflammatory bowel disease: Prevalence and associated factors in adolescent and adult patients. Dig Liver Dis. 2017;49:405-11.

30. Gerasimidis K, Barclay A, Papangelou A, Missiou D, Buchanan E, Tracey C, et al The epidemiology of anemia in pediatric inflammatory bowel disease: prevalence and associated factors at diagnosis and follow-up and the impact of exclusive enteral nutrition. Inflamm Bowel Dis. 2013;19:2411-22.
31. Alves RA, Miszputen SJ, Figueiredo MS. Anemia in inflammatory bowel disease: prevalence, differential diagnosis and association with clinical and laboratory variables. Sao Paulo Med J. 2014;132:140-6.

32. Burisch J, Vegh Z, Katsanos KH, Christodoulou DK, Lazar D, Goldis A, et al. Occurrence of Anaemia in the First Year of Inflammatory Bowel Disease in a European Population-based Inception Cohort-An ECCO-EpiCom Study. J Crohns Colitis. 2017;11:1213-22.

33. Kaniewska M, Bartnik W, Gonciarz M, Kłopocka M, Linke K, Małecka-Panas $\mathrm{E}$, et al. Iron deficiency anaemia in patients with inflammatory bowel disease: National Consultant for Gastroenterology Working Group Recommendations. Prz Gastroenterol. 2014;9:259-63.

34. Bengi G, Keyvan H, Durmaz SB, Akpinar H. Frequency, types, and treatment of anemia in Turkish patients with inflammatory bowel disease. World J Gastroenterol. 2018;24:4186-96.

35. Goodhand JR, Kamperidis N, Rao A, Laskaratos F, McDermott A, Wahed M, et al. Prevalence and management of anemia in children, adolescents, and adults with inflammatory bowel disease. Inflamm Bowel Dis. 2012;18:513-9.

36. Michailidou M, Nfonsam VN. Preoperative anemia and outcomes in patients undergoing surgery for inflammatory bowel disease. Am J Surg. 2018;215: 78-81.

37. Stein J, Aksan A, Farrag K, Dignass A, Radeke HH. Management of inflammatory bowel disease-related anemia and iron deficiency with specific reference to the role of intravenous iron in current practice. Expert Opin Pharmacother. 2017; 18:1721-37. 